\title{
The diagnostic usefulness of the basophil activation test (BAT) with annexin $V$ in an allergy to Alternaria alternata
}

\author{
Emilia Królewicz, ${ }^{1, B-D}$, Krzysztof Gomułka 2,B, Anna Wolańczyk-Mędrala, ${ }^{2, B}$, \\ Wojciech Mędrala ${ }^{2, A, C}$, Wojciech Barg ${ }^{3, B}$, Irena Kustrzeba-Wójcicka ${ }^{1, E, F}$ \\ ${ }^{1}$ Department of Medical Biochemistry, Wroclaw Medical University, Poland \\ 2 Department of Internal Diseases and Allergology, Wroclaw Medical University, Poland \\ ${ }^{3}$ Department of Physiology, Wroclaw Medical University, Poland \\ A - research concept and design; $B$ - collection and/or assembly of data; $C$ - data analysis and interpretation; \\ $D$ - writing the article; $E$ - critical revision of the article; $F$ - final approval of the article
}

\section{Address for correspondence \\ Emilia Królewicz \\ E-mail:emilia_krolewicz@wp.pl}

Funding sources

None declared

Conflict of interest

None declared

Received on July 3,2017

Reviewed on October 8, 2017

Accepted on 0ctober 12, 2017

DOI

10.17219/acem/78563

\section{Copyright}

Copyright by Author(s)

This is an article distributed under the terms of the

Creative Commons Attribution Non-Commercial License

(http://creativecommons.org/licenses/by-nc-nd/4.0/)

\begin{abstract}
Background. The basophil activation test (BAT) is an effective diagnostic tool in mold allergy, which is still not sufficiently known.

Objectives. The aim of our study was to assess the degree of annexin $V$ binding to the surface of the basophil cell membrane after stimulation with anti-immunoglobulin $\mathrm{E}$ (anti-lgE) and Alternaria alternata allergenic extract.
\end{abstract}

Material and methods. Alternaria alternata allergic patients $(n=32)$ and healthy volunteers $(n=33)$ were evaluated using skin prick tests (SPT), quantification of specific lgE (slgE) and the BAT. Basophil activation was detected as a percentage degree of annexin $V$ binding to the surface of the basophil cell membrane.

Results. Receiver operating characteristic (ROC) curve analysis yielded a threshold value of $4.95 \%$ of activated basophils when the tested group and control group were studied, with a sensitivity and specificity of 100\% (area under curve $(A \cup C)=1 ; p=0.00000$ ) for $100 \mathrm{SBU} / \mathrm{mL}$ Alternaria alternata allergen extract. The threshold value was $10.28 \%$ with a sensitivity of $93.8 \%$ and specificity of $100 \%$ (AUC $=0.98958 ; p=0.00000$ ) for $10 \mathrm{SBU} / \mathrm{mL}$ mold extract, and $9.37 \%$ with a sensitivity of $90.3 \%$ and specificity of $100 \%$ (AUC $=0.96307$; $p=0.00000$ ) for $1 \mathrm{SBU} / \mathrm{mL}$ Alternaria alternata allergen extract. The method was least efficacious in antiIgE stimulation, where the threshold value was $5.48 \%$ with a sensitivity of $90.6 \%$ and specificity of $30.3 \%$ $(A \cup C=0.46780 ; p=0.67039)$.

Conclusions. The BAT with annexin V and slgE measurement against Alternaria alternata increase the capability of a diagnostic laboratory for detecting mold sensitization. Both methods may certainly replace SPT, which are currently routinely used in allergy diagnosis. Annexin V may be considered a new basophil activation marker with an efficacy comparable to that of CD63 or CD203C.

Key words: Alternaria alternata allergy, basophil activation test, specific immunoglobulins E, flow cytometry, receiver operating characteristic curve 


\section{Introduction}

The basophil activation test (BAT) is a modern and promising research tool in the field of medical immunology. It was introduced to flow cytometry in 1994 by Sainte-Laudy et al. ${ }^{1}$ The assessment of basophil activity during stimulation with an allergen or other causative agent is an in vitro method that raises special interest among scientists. The BAT uses various markers for the identification and activation of basophils. Currently, the gold standard in this field is the evaluation of CD63 expression as a de novo molecule after antigen activation. ${ }^{2,3}$ The CD63 antigen was used in studies with various inhalant allergens: mites, grasses,animal dander,in allergy to insect venom and to drugs. ${ }^{4-14}$ CD203c is the second antigen used in scientific research as a double marker of both identification and activation of basophils, occurring constantly on its surface. ${ }^{15-17}$ Other antigens, such as CD13, CD45, CD107a, and CD164, are also well-known and used in scientific experiments. ${ }^{18,19}$ However, no objective studies have so far compared the properties and diagnostic efficacy of most of these markers. Although the BAT has been used in allergology for over 20 years, work continues on improving the protocols for basophil identification. The lack of standardization of experiments using various antigens remains the main problem, causing discrepancies and fundamental differences in test results. In the area of laboratory research, a constant search continues for new and effective markers which could improve modern allergy diagnostics. Cytometry studies may provide an opportunity to develop mold allergy detection, including Alternaria alternata hypersensitivity. Although Alternaria allergies are fairly frequent, with an occurrence of $3-20 \%$ in Europe and $47 \%$ in the Polish population, knowledge about molecular mold allergy detection is still insufficient. ${ }^{20}$

In this paper, we investigated if annexin $\mathrm{V}$ may be considered a new basophil activation marker, useful in Alternaria alternata allergy detection.

Basophil activation was demonstrated by using the phenomenon of basophil membrane reorganization under the influence of applied stimuli. In this process, phosphatidylserine, as the main constitutive phospholipid, is displaced from the cytosolic to the basophil external membrane site. Using annexin $\mathrm{V}$ bound to fluorochrome, which is the ligand for phosphatidylserine, it was proven that a colored complex forms, which may be depicted in a flow cytometer. The only fluorescent cells were those bounded to annexin $\mathrm{V}$, i.e., activated basophils.

Our studies are a reference to the experiments conducted by Sainte-Laudy and Ouk, who demonstrated changes in the conformation of the basophil membrane after activation with specific and nonspecific stimuli. ${ }^{21}$

\section{Material and methods}

\section{Patients and controls}

A total of 32 patients (17 males and 15 females) aged from 17 to 42 years (median: 25 years) with seasonal allergic rhinitis and positive skin prick tests (SPT) to the Alternaria alternata allergen mix (Allergopharma, Joachim Ganzer KG, Reinbek, Germany) were included in the study. Control group consisted of 33 healthy volunteers ( 9 males and 24 females) aged from 19 to 54 years (median: 23 years) with no allergic symptoms and with negative SPT results. All the procedures were performed in accordance with the ethical standards of the Helsinki Declaration. The study was approved by the Ethics Committee of Wroclaw Medical University, Poland. Informed consent was obtained from all the enrolled individuals.

\section{Skin prick tests}

Skin prick tests were performed according to the standard procedure, using the panel of inhalant allergen extracts (Allergopharma, Joachim Ganzer KG). The kit of reagents contained Alternaria alternata, Cladosporium herbarum, Aspergillus fumigatus, and Penicilium notatum extracts at a concentration of $10,000 \mathrm{SBU} / \mathrm{mL}$, histamine hydrochloride $1.7 \mathrm{mg} / \mathrm{mL}$ and sodium chloride $9 \mathrm{mg} / \mathrm{mL}$ were used as a positive and negative control. The SPT results were read after $15 \mathrm{~min}$ and considered positive if the wheal diameter was $>3 \mathrm{~mm}$.

\section{Specific immunoglobulins E measurement}

Specific immunoglobulins E (sIgE) against the Alternaria alternata allergen mix $\mathrm{m} 6$ were determined by the ImmunoCAP FEIA system measurements (Thermo Fisher Scientific Inc., Uppsala, Sweden) according to the manufacturer's instruction. The detection range was $0.35-100 \mathrm{kU} / \mathrm{L}$. Values $\geq 0.35 \mathrm{kU} / \mathrm{L}$ were considered positive.

\section{Basophil activation test protocol}

Blood specimens were collected into K-EDTA venipuncture tubes (Sarstedt AG \& Co, Nümbrecht, Germany) and used for cell stimulation in BD Falcon Round Bottom Tubes (BD Biosciences, San Diego, USA). Testing samples were performed for each patient as the patient background $(\mathrm{Pb})$, positive (stimulation) control (Pc) with Polyclonal Rabbit anti-Human IgE antibody at a final concentration of $10 \mu \mathrm{g} / \mathrm{mL}$ (Dako Denmark A/S, Glostrup, Denmark) and with the Alternaria alternata allergen mix used in SPT at the 3 final concentrations of 100, 10 and $1 \mathrm{SBU} / \mathrm{mL}$, identified as $\mathrm{C}_{1}, \mathrm{C}_{2}$ and $\mathrm{C}_{3}$. 


\section{Sample preparation and analysis}

At the beginning of the experiment, $50 \mu \mathrm{L}$ of stimulation control anti-Human IgE and $50 \mu \mathrm{L}$ of corresponding Alternaria alternata allergen solution was added to $100 \mu \mathrm{L}$ of stimulation buffer and marked as Pc, $C_{1}, C_{2}$, and $C_{3}$ probe. Only $150 \mu \mathrm{L}$ stimulation buffer was added to the background probe $\mathrm{Pb}$. In the next step, $50 \mu \mathrm{L}$ of the patient's whole blood was added to each tube and gently mixed. To analyze basophil activation, cells were stained with $5 \mu \mathrm{L}$ of annexin V-FITC (BD Biosciences) and $5 \mu \mathrm{L}$ of anti-CCR3-PE (R\&D Systems, Minneapolis, USA), and the samples were incubated for $15 \mathrm{~min}$ at $37^{\circ} \mathrm{C}$. Then, stimulation was terminated by adding $2 \mathrm{~mL}$ of Lysing Solution (BD Biosciences) after which the mixing tubes were incubated at room temperature for $10 \mathrm{~min}$. After centrifugation (5 min, $500 \mathrm{~g}$ ), supernatants were decanted and cell pellets were resuspended in $300 \mu \mathrm{L}$ of Cell Wash (BD Biosciences) and gently mixed. A total amount of 100,000 cells were acquired per sample using the FACScan flow cytometer (BD Biosciences).

The data was analyzed using CellQuest flow cytometry analysis software (BD Biosciences) according to the manufacturer's instructions. Basophils were identified following the CCR $3^{\text {high }} / \mathrm{SSC}^{\text {low }}$ BAT protocol (Fig. 1).

The percentage degree of annexin $\mathrm{V}$ binding to the surface of the basophil cell membrane after stimulation with anti-Human IgE and Alternaria alternata allergenic extract was defined as basophil activation. The calculation of the percentage of annexin $\mathrm{V}$ binding expression was detected as brightly fluorescent fluorescein isothiocyanate (FITC) (Fig. 2). The activated cells were identified by comparison of their number to the total amount of basophil population gated (Fig. 1). The results were presented after subtracting patient background values.

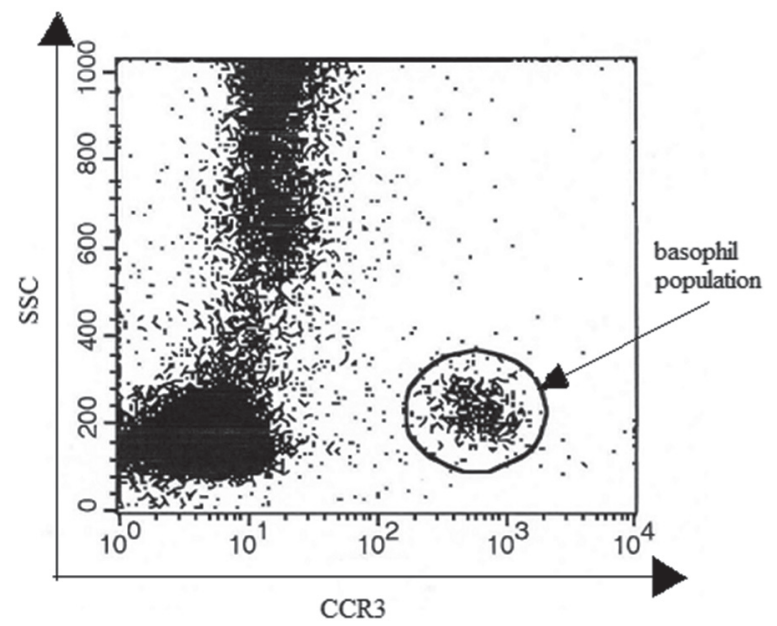

Fig. 1. Basophil population gating

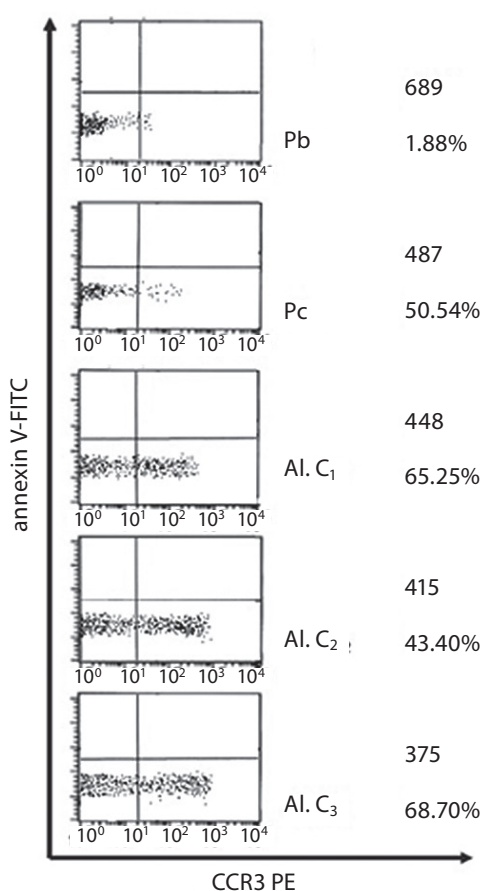

Fig. 2. The number and percentage of activated basophils in each probe in selected individuals in the study group

FITC - fluorescein isothiocyanate; $\mathrm{Pb}$ - patient background; $\mathrm{PC}$ - positive control; Al. - allergen; $C_{1}, C_{2}, C_{3}$ - the concentrations of the Alternaria alternata allergen mix (100, 10 and $1 \mathrm{SBU} / \mathrm{mL}$, respectively).

\section{Statistical analysis}

Statistical analysis was performed with the use of STATISTICA v. 12.5 software (StatSoft, Kraków, Poland). The distribution of data was performed using the Shapiro-Wilk test. Due to the lack of a normal distribution, the nonparametric Mann-Whitney test was used for the comparison of 2 independent samples. Probability values $\mathrm{p}<0.05$ were considered significant. The optimal cut-off values for allergen stimulation, sensitivity and specificity were determined using receiver operating characteristic (ROC) curve analysis. ${ }^{22}$

\section{Results}

\section{Skin prick tests}

The results of the SPT with histamine hydrochloride in the study group $(\mathrm{n}=32)$ ranged from a $3 \mathrm{~mm}$ to a $6 \mathrm{~mm}$ wheal diameter (median: $4 \mathrm{~mm}$ ). In the control group $(\mathrm{n}=33)$, the results were within the $3-5.5 \mathrm{~mm}$ range (median: $3.5 \mathrm{~mm}$ ). There were no statistically significant differences in SPT with histamine hydrochloride between the groups $(\mathrm{p}=0.12721)$.

The results of SPT with Alternaria alternata extract in the control group were completely negative and reached $0 \mathrm{~mm}$ for each volunteer, while in the study group the results ranged from $3.5 \mathrm{~mm}$ to $11 \mathrm{~mm}$ (median: $6.5 \mathrm{~mm}$ ). 


\section{Specific immunoglobulins $E$}

Specific immunoglobulins E concentration to the Alternaria alternata allergen mix m6 in the control group $(\mathrm{n}=33)$ were within the range of $0-0.06 \mathrm{kU} / \mathrm{L}$ (median: $0.01 \mathrm{kU} / \mathrm{L})$. In the case of patients with mold allergy $(\mathrm{n}=32)$, the results obtained were in the range of $0.002-28.2 \mathrm{kU} / \mathrm{L}$ (median: $5.47 \mathrm{kU} / \mathrm{L}$ ).

Specific IgE concentrations acquired in $\mathrm{kU} / \mathrm{L}$ were qualified for assigned classes from 0 to 6 according to the manufacturer's instruction. A result was considered positive if the concentration of $\operatorname{sIgE}$ was $\geq 0.35 \mathrm{kU} / \mathrm{L}$, which was interpreted as a low result in class 1 .

In the study group $(\mathrm{n}=32), 27$ positive and 5 negative results of SIgE to Alternaria alternata were obtained (Table 1).

Table 1. Specific immunoglobulins E (lgE) concentration to Alternaria alternata in the study group $(n=32)$ by grade of CAP classes

\begin{tabular}{|l|c|c|}
\hline $\begin{array}{c}\text { slgE concentration } \\
\text { [kU/L] }\end{array}$ & CAP class & Study group $(\mathrm{n}=32)$ \\
\hline$>100$ & 6 & 0 \\
\hline From 50 to $<100$ & 5 & 0 \\
\hline From 17.5 to $<50$ & 4 & $3(9.38 \%)$ \\
\hline From 3.5 to $<17.5$ & 3 & $15(46.88 \%)$ \\
\hline From 0.7 to $<3.5$ & 2 & $7(21.88 \%)$ \\
\hline From 0.35 to $<0.7$ & 1 & $2(6.25 \%)$ \\
\hline$<0.35$ & 0 & $5(15.63 \%)$ \\
\hline
\end{tabular}

slgE - specific immunoglobulin E.

\section{Flow cytometry studies}

\section{Basophil number}

The number of basophils identified in the whole tested population $(\mathrm{n}=65)$ ranged from 108 to 872 cells (median: 488).

\section{Basophil activity}

The activity of basophils in each probe was determined as the percentage of active cells of the whole identified basophil population.

\section{Patient background}

The median of $\mathrm{Pb}$ in the tested population $(\mathrm{n}=65)$ was $1.75 \%$ ( $\min 1.33 \%, \max 1.98 \%$; standard deviation (SD): 0.14\%). The mean value of $\mathrm{Pb}$ increased by a value of $2 \mathrm{SD}(\mathrm{X}+2 \times \mathrm{SD})$ was adopted as the cut-off point and reached $2.04 \%$.

\section{Positive control}

In the study group $(\mathrm{n}=32)$, the percentage degree of annexin $\mathrm{V}$ binding to the surface of the basophil cell membrane after stimulation with anti-Human IgE was $14.26 \%$ (min 2.95\%, $\max 76.01 \%$ ). The results of Pc in the healthy volunteers were slightly higher than in the patients. After anti-Human IgE stimulation, the median of basophil activation reached $21.69 \%$ ( $\min 2.08 \%$, $\max 83.68 \%$ ), but the difference was not statistically significant $(p=0.66025)$.

\section{Stimulation using Alternaria alternata extract}

In the group of Alternaria alternata allergic patients $(\mathrm{n}=32)$, the median percentage of basophil activation at the highest concentration, $\mathrm{C}_{1}=100 \mathrm{SBU} / \mathrm{mL}$, was $20.42 \%$ (min 6.73\%, $\max 74.70 \%$ ). At the intermediate concentration of mold allergen extract, $\mathrm{C}_{2}=10 \mathrm{SBU} / \mathrm{mL}$, the median expression of annexin $\mathrm{V}$ binding reached $21.89 \%$ ( $\min 3.14 \%$, max 85.92\%). Stimulation at the lowest concentration of Alternaria extract, $\mathrm{C}_{3}=1 \mathrm{SBU} / \mathrm{mL}$, gave the highest median of basophil activation, 29.41\% (min 2.31\%, $\max 88.55 \%$ ). In the control group, the results of the BAT were considerably lower. The highest Alternaria alternata extract concentration $\left(\mathrm{C}_{1}\right)$ resulted in a median at the level of $2.31 \%$ (min $1.04 \%$, max $5.48 \%$ ). Stimulation by the $\mathrm{C}_{2}$ concentration resulted in a median of basophil activation equal to $2.46 \%$ ( $\min 1.51 \%, \max 4.83 \%)$. In the case of mold allergen extract at the $\mathrm{C}_{3}$ concentration, the median of annexin $\mathrm{V}$ binding to the basophil surface reached 2.54\% ( $\min 1.06 \%, \max 5.96 \%$ ). There were statistically significant differences in basophil activity between the 2 tested groups in $C_{1}, C_{2}$ and $C_{3}$ probes $(p<0.05)$. The cut-off value for antiIgE, and allergen stimulation positivity and specificity was determined on the basis of ROC curves and reached $5.45 \%$ for anti-IgE, $4.95 \%$ at the $\mathrm{C}_{1}$ concentration, $10.28 \%$ at the $\mathrm{C}_{2}$ concentration, and $9.37 \%$ at the $\mathrm{C}_{3}$ concentration (Fig. 3).

\section{Sensitivity and specificity}

Based on ROC curves, it was demonstrated that the method achieved its lowest effectiveness for the Pc sample. The sensitivity and specificity evaluated together were $120.9 \%$.

The highest sensitivity and specificity of the BAT was achieved for the highest concentration of Alternaria alternata extract, $\mathrm{C}_{1}=100 \mathrm{SBU} / \mathrm{mL}$. In this case, the sensitivity and specificity evaluated together were $200 \%$.

The analysis of ROC curves for the allergen stimulated probes was carried out on the basis of the calculated significance level (p) and area under ROC curve (AUC). A comparison of the results is demonstrated in Table 2.

\section{The dependence of activated basophil percentage on the concentration of Alternaria alternata allergen extract}

It has been shown that in both tested groups and in the control group, the highest mean value and median of activated basophils was achieved by stimulation with the lowest concentration of Alternaria alternata extract, $\mathrm{C}_{3}=1 \mathrm{SBU} / \mathrm{mL}$ (Fig. 4). 

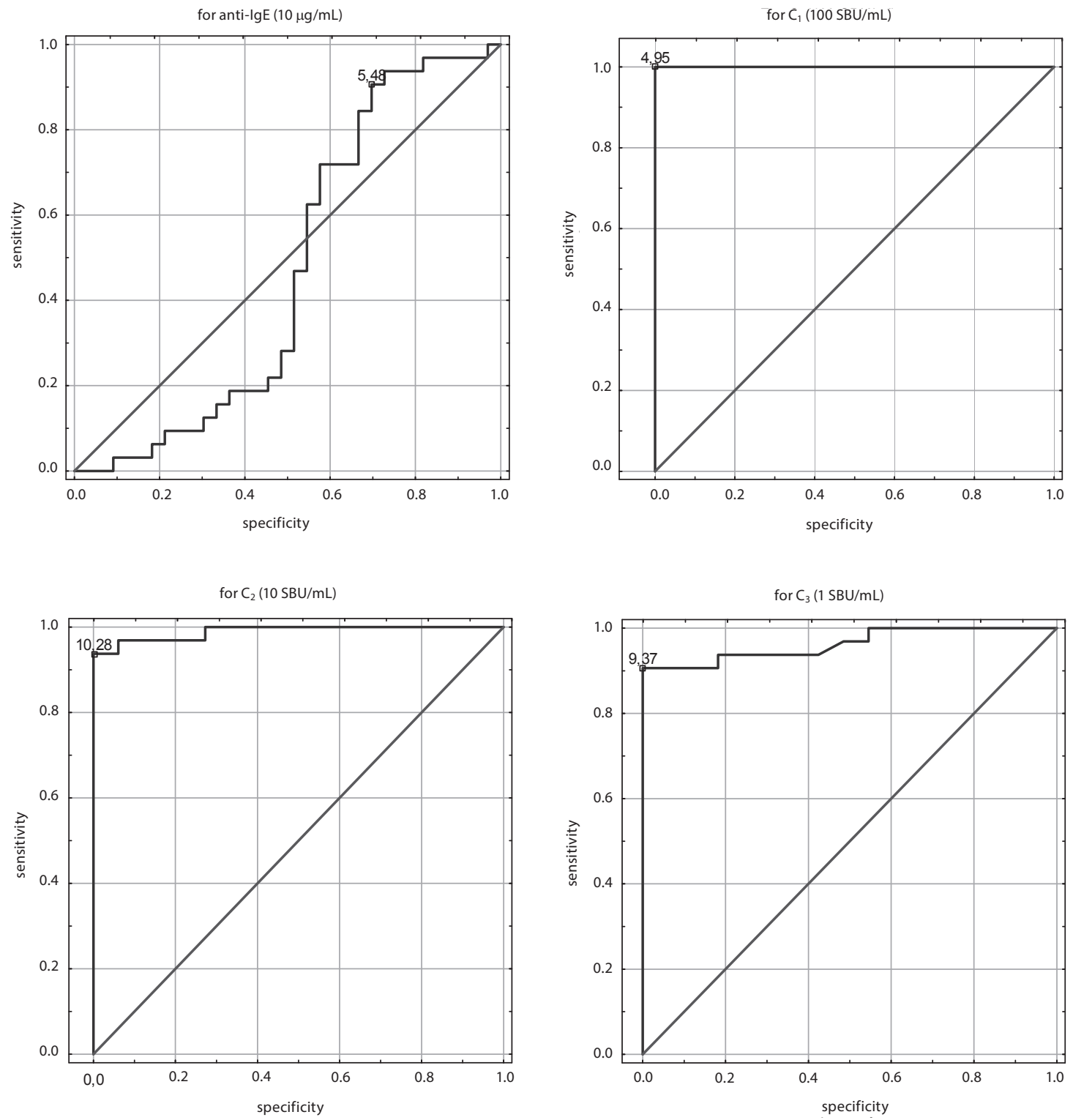

Fig. 3. Receiver operating characteristic (ROC) curves with cut-off value for basophil stimulation with anti-immunoglobulin $\mathrm{E}$ (anti-lgE) and Alternaria alternata allergen extract

$C_{1}, C_{2}, C_{3}$ - the concentrations of the Alternaria alternata allergen mix (100, 10 and $1 \mathrm{SBU} / \mathrm{mL}$, respectively).

Table 2. The comparison of sensitivity, specificity, p-value, and AUC for the allergen-stimulated probes

\begin{tabular}{|l|c|c|c|c|c|}
\multicolumn{1}{c|}{ Probe } & Sensitivity [\%] & Specificity [\%] & $\begin{array}{c}\text { The sum of sensitivity } \\
\text { and specificity [\%] }\end{array}$ & p-value & AUC \\
\hline PC & 90.6 & 30.3 & 120.9 & 0.67039 & 0.46780 \\
\hline$C_{1}$ & 100 & 100 & 200 & 0.00000 & 1 \\
\hline$C_{2}$ & 93.8 & 100 & 193.8 & 0.00000 & 0.98958 \\
\hline$C_{3}$ & 90.6 & 100 & 190.6 & 0.00000 & 0.96307 \\
\hline
\end{tabular}

PC - positive control; $C_{1}, C_{2}, C_{3}$ - the concentrations of the Alternaria alternata allergen mix (100, 10 and $1 \mathrm{SBU} / \mathrm{mL}$, respectively); $A U C$ - area under receiver operating characteristic curve.

\section{Discussion}

The aim of this study was to evaluate and optimize the diagnostic usefulness of the BAT in Alternaria alternata allergies. We also investigated if annexin $\mathrm{V}$ could be considered a new basophil activation marker and if it might replace the antigens commonly used in cell tests, such as CD63 or CD203c.

The studies were performed in a group of 65 people, of whom 32 patients were sensitized to Alternaria alternata; they had positive results of SPT and presented clinical symptoms. The remaining 33 healthy volunteers 


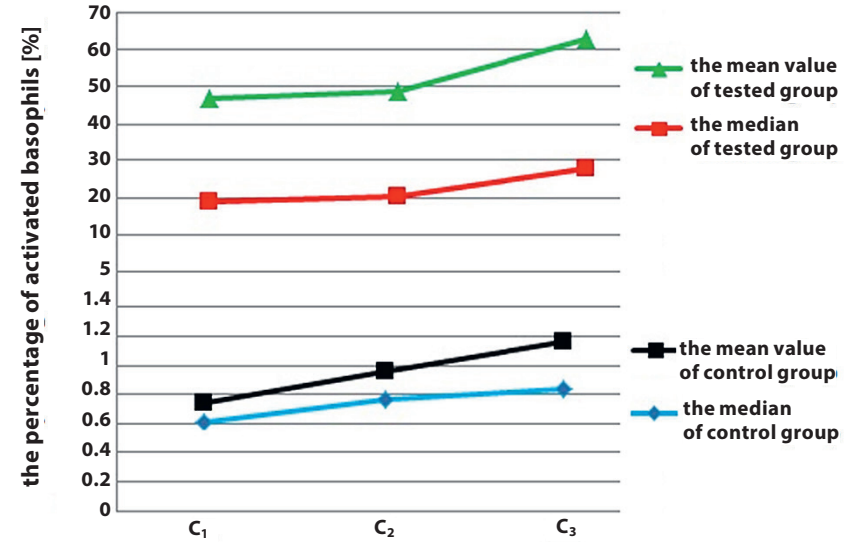

Fig. 4. The distribution of the mean value and median of basophil activity in the tested and control groups $(n=65)$

$C_{1}, C_{2}, C_{3}$-the concentrations of the Alternaria alternata allergen mix (100, 10 and $1 \mathrm{SBU} / \mathrm{mL}$, respectively).

had totally negative results of the SPT and did not present symptoms of allergy-based diseases.

The results of specific IgE measurement directed against the Alternaria alternata allergen extract m6 were interesting. Out of 32 patients allergic to Alternaria mold with positive SPT results, as many as 5 persons had a sIgE anti-m6 result $<0.35 \mathrm{kU} / \mathrm{L}$, i.e., below the lower limit of concentration at which the result is considered positive and qualified as class $1 \mathrm{sIgE}$. In the tested group, in more than 15\% of allergic patients, the concentration of sIgE was in class 0 and the remaining more than $84 \%$ of patients were in classes 1-4. The highest percentage of patients sensitized to Alternaria had a high level of IgE, qualified as class 3 , and they accounted for over $46 \%$ of the studied group. After a comparison between the results of SPT and sIgE values, it was observed that the sIgE class is not correlated to the size of the wheal, the diameter of which is interpreted in SPT. In some respondents, the SPT result with the Alternaria alternata extract was $12 \times 10 \mathrm{~mm}$, in others it was $6 \times 7 \mathrm{~mm}$ or $5 \times 5 \mathrm{~mm}$, but in each case, the sIgE value was qualified as class 3. Moreover, there were allergic patients in the tested group for whom the results of the SPT reached $8 \times 7 \mathrm{~mm}$, while the sIgE value was qualified as class 0 . In the whole control group, the result was negative, as the concentration of sIgE against Alternaria alternata was $<0.35 \mathrm{kU} / \mathrm{L}$. It was proven that the concentration of sIgE anti-m 6 in the studied group was significantly higher than in the control group, where the min, max and median were equal to $0 \mathrm{~mm}$ ( $\mathrm{p}=0.00000)$. The results of Alternaria alternata sIgE quantification demonstrated a sensitivity of $90.6 \%$ and a specificity of $100 \%$. Currently, in order to increase the sensitivity and specificity of IgE measurement, shifting of the lower concentration of sIgE from $0.35 \mathrm{kU} / \mathrm{L}$ to $0.1 \mathrm{kU} / \mathrm{L}$ is contemplated. However, according to the instructions for interpreting the results of the ImmunoCAP FEIA system (Thermo Fisher Scientific Inc.), the value of $0.35 \mathrm{kU} / \mathrm{L}$ is still regarded as the threshold.
The first parameter analyzed in the cytometry studies conducted was the number of cells identified as basophils. Bühlmann Laboratories AG (Schönenbuch, Switzerland) notes that in cell tests, the number of gated basophils should be within the range of 200-600. In the experiment, the median of identified basophils (median: 488) in each sample in the tested and control group $(n=65)$ was contained in the range specified by the manufacturer, but in some unstimulated and stimulated samples, less than 200 or more than 600 of basophils were collected.

The main objective of the cytometry study was to demonstrate that the binding of annexin $\mathrm{V}$ depends on the activation of basophils after stimulation with anti-IgE and the Alternaria alternata allergen extract. The displacement of phosphatidyl serine as a ligand for annexin $\mathrm{V}$ from the cytosolic to the basophil external membrane site occurs only under the influence of applied stimuli.

The median of basophil activity in unstimulated samples, $\mathrm{Pb}$, was similar in the tested group (1.77\%) and in healthy volunteers $(1.75 \%)$. These results are comparable to the values obtained by De Weck et al., who indicated that the basophil activity at rest is generally below $5 \%{ }^{16}$

No statistically significant differences between the groups studied were observed after anti-Human IgE stimulation ( $\mathrm{p}=0.66025)$. The positive control stimulation gave median results equal to $14.26 \%$ in the tested group vs $21.69 \%$ in the control group.

Receiver operating characteristic curve analysis was performed to determine the cut-off value of the percentage of activated basophils between Alternaria alternata-sensitized patients and controls. The positive control stimulation with anti-IgE gave unsatisfactory results, because the specificity reached only $30.3 \%$ and the sensitivity was $90.6 \%$ (AUC $=0.46780 ; \mathrm{p}=0.67039)$. Among the participants there were 6 persons with a negative reaction to anti-IgE below the cut-off value of $5.48 \%$. The threshold was established at $4.95 \%$ for $C_{1}=100 \mathrm{SBU} / \mathrm{mL}$ mold extract concentration with a sensitivity and specificity of $100 \%$ ( $A U C=1 ; p=0.00000)$. The analysis of the data obtained with $\mathrm{C}_{2}=10 \mathrm{SBU} / \mathrm{mL}$ allergen extract defined a cut-off value of $10.28 \%$ activated basophils with a sensitivity of $93.8 \%$ and a specificity of $100 \%$ (AUC = 0.98958; $\mathrm{p}=0.00000$ ). Sensitivity reached $90.3 \%$ with a specificity of $100 \%$ concerning $\mathrm{C}_{3}=1 \mathrm{SBU} / \mathrm{mL}$ Alternaria alternata allergen extract with a threshold of 9.37\% (AUC = 0.96307; $\mathrm{p}=0.00000)$. In all healthy volunteers $(\mathrm{n}=33)$, the results of stimulation with the mold allergen extract were negative.

In the BAT, the dependence between the degree of IgEdependent activation and the value of the concentration of a specific stimulus was variable between individuals. It was assumed that each allergen is characterized by the curve of the dependence of its concentration on the degree of basophil activation. Kleine-Tebbe et al. demonstrated that in the initial phase of the experiment, an increase in the concentration of the allergen causes an increase of basophil activation. Then there is a plateau on the curve, 
after which a further increase in the concentration of the allergen causes a decrease of basophil activation. ${ }^{23}$ It has been proven that in the tested and control group, the highest percentage of activated basophils was observed at the lowest concentration of the mold allergen extract $C_{3}=1$ $\mathrm{SBU} / \mathrm{mL}$ (Fig. 4). In the tested group, the basophil activation in each of the 3 concentrations of the Alternaria alternata extract was in the range from a dozen to several dozen percent, while in the control group it extended slightly above or below $1 \%$. The mold allergen extract caused basophil activation only in people allergic to Alternaria.

Currently, only a few works describe the BAT performed with mold allergens. Not all researchers have utilized standardized and calibrated allergens in cell tests. Although they are free from preservatives and other cytotoxic additives, their use is expensive. In our studies, we used the Alternaria alternata allergen extract intended for SPT. Therefore, a comparison of the results of our studies with the effects of the experiments presented in the literature is possible only to a limited extent. In the paper presented by Mirković et al., a CD203c marker was used for Aspergillus fumigatus allergy detection and for allergic bronchopulmonary aspergillosis diagnosis in cystic fibrosis patients. ${ }^{24}$ However in this study, the sensitivity and specificity of the BAT were not appointed. It has been proven that the combination of BAT with CD203c and routine measurement of total and specific IgE increases the correct classification of patients into subgroups of unsensitized persons, allergic to Aspergillus and aspergillosis-affected.

The results obtained may be compared to the results of experiments with other allergens and basophil activation markers. Sanz et al., in a protocol of BAT using anti-IgE/anti-CD63, mite allergen Dermatophagoides pteronyssinus and grass fodder Lolium perenne obtained a sensitivity equal to $93.3 \%$ and a specificity of $98.7 \% .{ }^{25}$ GonzálezMuñoz et al. also conducted research in the direction of flow cytometry to detect mite allergy, using anti-CD123/anti-CD63. For allergens at a higher concentration $(16 \mu \mathrm{g} / \mathrm{mL})$ they received sensitivity and specificity of $100 \%$, and in the case of a lower concentration $(1.6 \mu \mathrm{g} / \mathrm{mL})$, sensitivity reached $83 \%$ and specificity did not change. ${ }^{26}$

The BAT with annexin V, anti-CCR3 and the Alternaria alternata allergen extract presented in this paper has a sensitivity and efficiency comparable to CD63, which is considered the gold standard in the in vitro cell tests used in allergology. It also has a higher diagnostic value than CD203c. Undoubtedly, the advantage of the flow cytometry study with annexin $\mathrm{V}$ is the cost, which is much lower than in the case of other markers used in research work. Developing experiments using this protein is therefore encouraging. Further work using the BAT with different markers and mold allergens is necessary in order to validate the method.

\section{References}

1. Sainte-Laudy J, Vallon C, Guérin JC. Analysis of membrane expression of the CD63 human basophil activation marker. Applications to allergologic diagnosis [in French]. Allerg Immunol (Paris). 1994;26(6): 211-214.

2. Netchiporouk E, Moreau L, Rahme E, Maurer M, Lejtenyi D, BenShoshan M. Positive CD63 basophil activation tests are common in children with chronic spontaneous urticaria and linked to high disease activity. Int Arch Allergy Immunol. 2016;171(2):81-88.

3. Masilamani M, Kamalakannan M, Sampson HA. Basophil degranulation assay. Methods Mol Biol. 2017;1592:139-146.

4. Leśniak M, Czarnobilska E. Usefulness of basophil activation test for the diagnosis of inhaled allergies [in Polish]. Przegl Lek. 2015;72(12): 773-778.

5. An S, Shen C, Liu X, et al. Alpha-actinin is a new type of house dust mite allergen. PloS ONE. 2013;8(12):e81377.

6. Korošec P, Silar M, Kopač $P$, Eržen R, Zidarn M, Košnik M. Distinct contributory factors determine basophil-allergen sensitivity in grass pollen rhinitis and in anaphylactic wasp venom allergy. Int Arch Allergy Immunol. 2016;171(2):89-101.

7. Wolańczyk-Mędrala A, Gogolewski G, Liebhart J, et al. A new variant of the basophil activation test for allergen-induced basophil CD63 upregulation. The effect of cetirizine. J Investig Allergol Clin Immunol. 2009;19(6):465-473.

8. Crockard AD, Ennis M. Laboratory-based allergy diagnosis: Should we go with the flow? Clin Exp Allergy. 2001;31(7):975-977.

9. Ocmant A, Peignois $Y$, Mulier S, Hanssens L, Michilis A, Schandené L. Flow cytometry for basophil activation markers: The measurement of CD203c up-regulation is as reliable as CD63 expression in the diagnosis of cat allergy. J Immunol Methods. 2007;320(1-2):40-48.

10. Herzinger T, Scharrer E, Placzek M, Przybilla B. Contact urticaria to giraffe hair. Int Arch Allergy Immunol. 2005;138(4):324-327.

11. Bidad K, Navijn MC, van Oosterhout AJ, van der Heide S, Elberink JN. Basophil activation test in the diagnosis and monitoring of mastocytosis patients with wasp venom allergy on immunotherapy. Cytometry B Clin Cytom. 2014;86(3):183-190.

12. Eberlein-König B, Rakoski J, Behrendt H, Ring J. Use of CD63 expression as marker of in vitro basophil activation in identifying the culprit in insect venom allergy. J Investig Allergo/Clin Immunol.2004;14(1):10-16.

13. Ariza A, FernandezTD, Doña I, et al. Basophil activation after nonsteroidal anti-inflammatory drugs stimulation in patients with immediate hypersensitivity reactions to these drugs. Cytometry A. 2014;85(5): 400-407.

14. Sudheer PS, Hall JE, Read GF, Rowbottom AW, Williams PE. Flow cytometric investigation of per-anaesthetic anaphylaxis using CD63 and CD203c. Anaesthesia. 2005;60:251-256.

15. Harada N, Hiragun M, Mizuno M, et al. A case of erythritol allergy studied by basophil histamine release and CD203c expression in vitro in addition to a challenge test in vivo. J Investig Allergol Clin Immunol. 2016;26(2):135-136.

16. De Weck A, Sanz ML, Gamboa PM, et al. Diagnostic tests based on human basophils: More potentials and perspectives than pitfalls. II. Technical issues. JInvestig Allergol Clin Immunol. 2008;18(3):143-155.

17. Boumiza R, Debard AL, Monneret $G$. The basophil activation test by flow cytometry: Recent developments in clinical studies, standardization and emerging perspectives. Clin Mol Allergy. 2005;3:9.

18. Wolańczyk-Mędrala A, Barg W, Mędrala W. CD 164 as a basophil activation marker. Curr Pharm Des. 2011;17(34):3786-3796.

19. Hennersdorf F, Florian S, Jakob A, et al. Identification of CD13, CD107a, and CD164 as novel basophil-activation markers and dissection of two response patterns in time kinetics of IgE-dependent upregulation. Cell Res. 2005;15(5):325-335.

20. Kustrzeba-Wójcicka I, Siwak E, Terlecki G, Wolańczyk-Mędrala A, Mędrala W. Alternaria alternata and its allergens: A comprehensive review. Clin Rev Allergy Immunol. 2014;47(3):354-365.

21. Sainte-Laudy J, Ouk C. Use of lipid rafting for the analysis of human basophil activation by flow cytometry. Inflamm Res. 2010;59(Suppl 2): S193-S195.

22. Pencina MJ, D'Agostino RB Sr, D'Agostino RB Jr, Vasan RS. Evaluating the added predictive ability of a new marker: From area under the ROC curve to reclassification and beyond. Stat Med. 2008;27(2): 157-172. 
23. Kleine-Tebbe J, Erdmann S, Knol EF, MacGlashan DW, Poulsen LK Gibbs BF. Diagnostic tests based on human basophils: Potentials, pitfalls and perspectives. Int Arch Allergy Immunol. 2006,141(1):79-90.

24. Mirković B, Lavelle GM, Azim AA, et al. The basophil surface marker CD203c identifies Aspergillus species sensitization in patients with cystic fibrosis. J Allergy Clin Immunol. 2016;137(2):436-443.
25. Sanz ML, Sánchez G, Gamboa PM, et al. Allergen-induced basophil activation: CD63 cell expression detected by flow cytometry in patients allergic to Dermatophagoides pteronyssinus and Lolium perenne. Clin Exp Allergy. 2001;31(7):1007-1013.

26. González-Muñoz M, Villota J, Moneo I. Analysis of basophil activation by flow cytometry in pediatric house dust mite allergy. Pediatr Allergy Immunol. 2008;19(4):342-347. 